\title{
Irrigation pricing policies and its impact on agricultural inputs demand in Tunisia: A DEA-based methodology
}

\author{
Aymen Frija ${ }^{\mathrm{a}, *, 1}$, Ada Wossink ${ }^{\mathrm{b}, 2}$, Jeroen Buysse ${ }^{\mathrm{a}, 1}$, Stijn Speelman ${ }^{\mathrm{a}, 1}$, Guido Van Huylenbroeck ${ }^{\mathrm{a}, 1}$ \\ ${ }^{a}$ Department of Agricultural Economics, Gent University, Coupure Links 653, 9000 Gent, Belgium \\ ${ }^{\mathrm{b}}$ The University of Manchester, Economics, School of Social Sciences, Arthur Lewis Building, Manchester M13 9PL, UK
}

\section{A R T I C L E I N F O}

Article history:

Available online 27 April 2011

\section{Keywords:}

Irrigation

Economic instruments

Demand management

Efficiency

\begin{abstract}
A B S T R A C T
This paper estimates farmers' individual irrigation water demand functions employing the information hidden in individual farmers' technical efficiency. This information is extracted through the development of a new deductive methodology based on inverse Data Envelopment Analysis (DEA) models. The empirical results for Tunisia show that farmers who are more technically efficient have less elastic irrigation water demand functions; these farmers would adjust demand only to a limited extent and they can afford the water price. In contrast, water pricing significantly affects those that are less efficient. These farmers shift towards a different cropping pattern using significantly less water and more land when the price of water increases. Thus, higher water prices would threaten this category's livelihood if their efficiency is not improved. However, if the technical efficiency of these farmers were to improve, then it would be more difficult to reach water saving objectives since their demand will also become highly inelastic. The findings have important implications in view of the objectives of Tunisia water policy which include:full cost recovery, continuity of the irrigation activity, and water saving at the national level.
\end{abstract}

Crown Copyright (c) 2011 Published by Elsevier Ltd. All rights reserved.

\section{Introduction}

According to neoclassical economic theory price increases of a good will cause a reduction of its demand. Therefore a farmer is also expected to respond to an increase in water price by reducing his consumption (Gómez-Limon and Riesgo, 2004). This results in a negatively sloped demand curve. Saved water could be either used by the more productive farmers, or reallocated to more productive non-agricultural water uses. Theoretically, such reallocation of the resource would certainly contribute to an increase in the overall efficiency of its use. In this respect, the apparent misuse and waste of irrigation water, in the context of low and subsidized water prices, caused policy makers and international funding institutions to advocate a more prominent role of economic incentives in encouraging efficient water use (Russell et al., 2007; Bar-Shira et al., 2006; Becker and Lavee, 2008; Perry, 2001; Speelman et al., 2009). Irrigation water pricing is then often regarded as a main tool to achieve a better level of water resource

\footnotetext{
* Corresponding author. Tel.: + 32926493 75; fax: +32 92646246.

E-mail address: frijaaymen@yahoo.fr (A. Frija)

1 Tel.: +32 926459 28; fax: +32 92646246 .

2 Tel.: +44161 275 4804; fax: +44161275 4812 .
}

valorization (Singh, 2007). The importance of irrigation water pricing can be twofold. Firstly, farmers will be more aware about the economic importance of the water and its scarcity and secondly, it provides incentives to farmers to think about shifting towards a more productive cropping pattern (Easter and Liu (2007); Perry (2001)).

The foregoing topic has received considerable attention in the applied literature. The practical importance of the pricing tool has been reviewed and criticized in many empirical studies of irrigation water demand functions, especially in arid countries (e.g., GómezLimón and Riesgo, 2004; Berbel and Gómez-Limón, 2000; VarelaOrtega et al., 1998). These studies show that water pricing would not always stimulate the desired changes in water use due to the low elasticity of demand for irrigation water. A limited effect is also expected if the cost of water is small, relative to total production costs. Besides, the implementation of water pricing could also engender collateral effects such as a decrease in agricultural income and labor demand in rural areas.

Some authors (Gómez-Limón and Berbel, 2000; Berbel and Gomez-Limon, 2000; Liao et al., 2007; and Molle et al., 2008) stress that for water pricing to be successful it is necessary to introduce a set of parallel policies to help improve the productivity of irrigation water to go in tandem with water pricing. Webber et al. (2008) state that the weakness of most of the present proposals for 
pricing irrigation water is that they intend to charge farmers for use of water without providing them a compensatory income. The purpose of such parallel policies is to improve the technical efficiency of farmers making them able to pay higher water rates. From a policy perspective this means that improved insight is required in the interaction of (a) economic incentives (water pricing), and (b) additional programmes to support the adoption of best management practices and water saving technologies.

This paper addresses the issues discussed above for Tunisia. In Tunisia, the government first started to implement water pricing in the irrigated areas in the 1970's. The main objective was to cover the operation and maintenance (O\&M) costs of the irrigation systems as a first step and to cover the full production cost of water in a later stage. Other more general objectives were to improve the valorization of the irrigation water by inducing a more technical efficient use and to reduce the total volume of water consumed by the agricultural sector $(80 \%$ of the total water consumption in the country) in order to face the forecasted imbalance between water supply and demand at the country level. However, the low level of farmers' revenue at that time was a main constraint for the introduction of water pricing. Thus, the government has developed a set of policies intended to improve the technical capacities and the productivity of farmers parallel to the pricing policy. Subsidies for water saving-technology adoption and enhancement of the extension services are the main examples. By 2004 the areas equipped with water saving technologies in Tunisia represented about $75 \%$ of the total irrigated area (Agency of Agricultural Investments Promotion, 2004). However, these subsidies have not resulted in significant water saving at the national level. In fact water saved through the higher efficiency was used to intensify the existing irrigated system (Bachta et al., 2000; Al Atiri, 2007).

This paper contributes to the literature in three ways. First, we develop a framework of the irrigated farm where technical inefficiency in production prevails and several production practices are available. The micro-economic framework shows the impact of water pricing and educational assistance to farmers on water demand in the situation of inefficiency. From the framework we hypothesize that improvement of farmers' technical capacities will lead to a more inelastic demand of irrigation water. This is in line with findings of other researches in the field of irrigation economics (Varela-Ortega et al., 1998; De Fraiture and Perry, 2002) who show that the most efficient farmers can better valorise irrigation water and therefore will be more able to support higher irrigation water prices than the less efficient farmers. It is important to note that technical efficiency is generally not the unique reason why farmers invest in such water saving technology. For instance, in addition to its water saving capacity, micro irrigation technology also allows precise management of the water and fertilizers needed to obtain higher yields and quality in addition to uniform products. Moreover, we hypothesize that smaller farms will face more constraints to improve their technical performances and therefore will be affected more negatively by increases of irrigation water prices. Consequently, when small-scale farms are predominant, water pricing could threaten the sustainability of the irrigated activity in a specific region or country.

The second contribution of this paper is to present an empirical analysis to test the hypotheses derived from our theoretical model. We build a normative inverse Data Envelopment Analysis (DEA) model in order to estimate the differential impact of higher water prices on the use of water and other inputs. The advantage of the inverse DEA model is its capacity to estimate individual demand functions by using the information hidden in the technical efficiency score of a particular farmer.

Third, we implement our empirical methodology for the Cap Bon region in Tunisia. We use our model in order to estimate demand functions for water and other inputs for farmer groups distinguished by their technical efficiency level. We then test the differential impact of the increasing nominal water prices of irrigation on the demand of water and other inputs for different types of farmers. The results are aggregated for different farm sizes and for different regional Water User Associations (WUA).

The article is structured as follows. The next section introduces the theory and hypotheses followed by the empirical method and the data, after which we report and then discuss the results of the statistical analysis. In the conclusions, we elaborate on the implications of our findings for water policy and for further research.

\section{Efficiency, extension activities and water pricing instruments}

The term "water use efficiency" like it is used in this article originates from the economic concept of productivity. Productivity measures the amount of any given resource that must be expended to produce one unit of any good or service. Water productivity might be measured by the volume of water used to produce a unit of output. In general, the lower the resource input requirement per unit, the higher the technical efficiency. Hence, improved water use efficiency in its simplest technical form means lowering the water needs to achieve a unit of production in any given activity. Therefore, water use efficiency improvement includes any measure that reduces the volume of water used per unit of any given activity, consistent with the maintenance or enhancement of water quality (Grafton, 2009).

Generally, in irrigated agriculture several crops and agronomic production practices are available that vary both in their economics and the water requirements. The importance of technology and inefficiencies for profitability and water use is illustrated for farm $A_{1}$ in Fig. 1. The technology available to farmer $A_{1}$ is represented by F. This frontier depicts the technically feasible set of economic performance (profit or farm income associated with production) and water use levels given the natural production environment as defined by climate/weather and soil type for this particular farmer. Profit $\pi_{0}$ and water use $W_{0}$ represent the skill with which producer $A_{1}$ is currently using the technology represented by $F$. Farmer $A_{1}$ is inefficient, he could maintain his profit while reducing water use to $W_{1}$. A further reduction in water use would decrease profit. An inefficiently large quantity of water is used because unlike for other

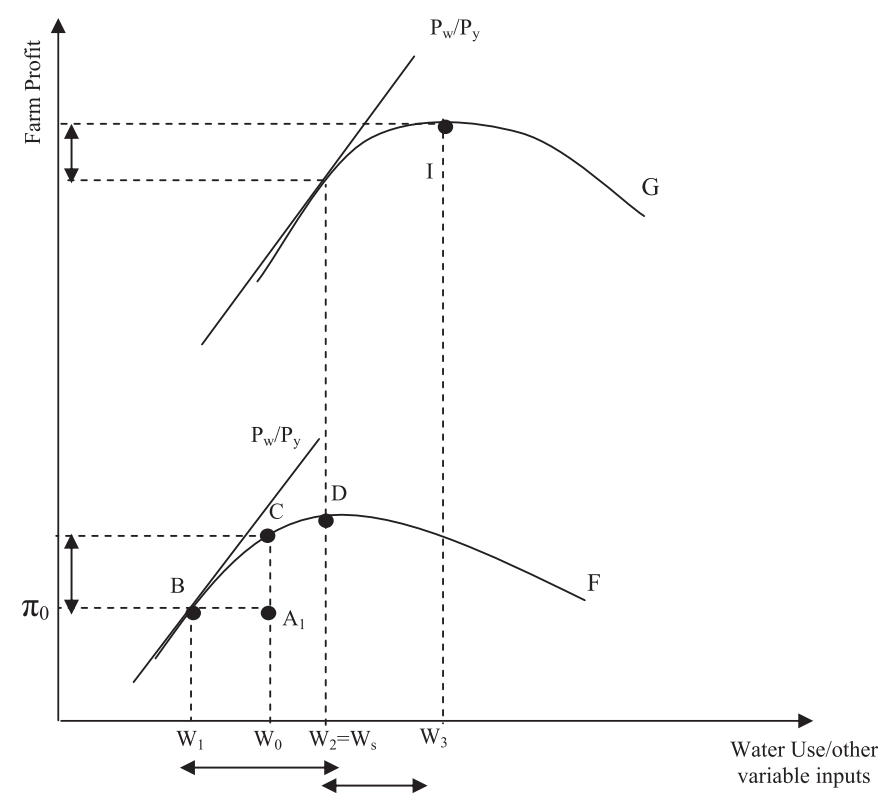

Fig. 1. Profitability frontier and water use inefficiency. 


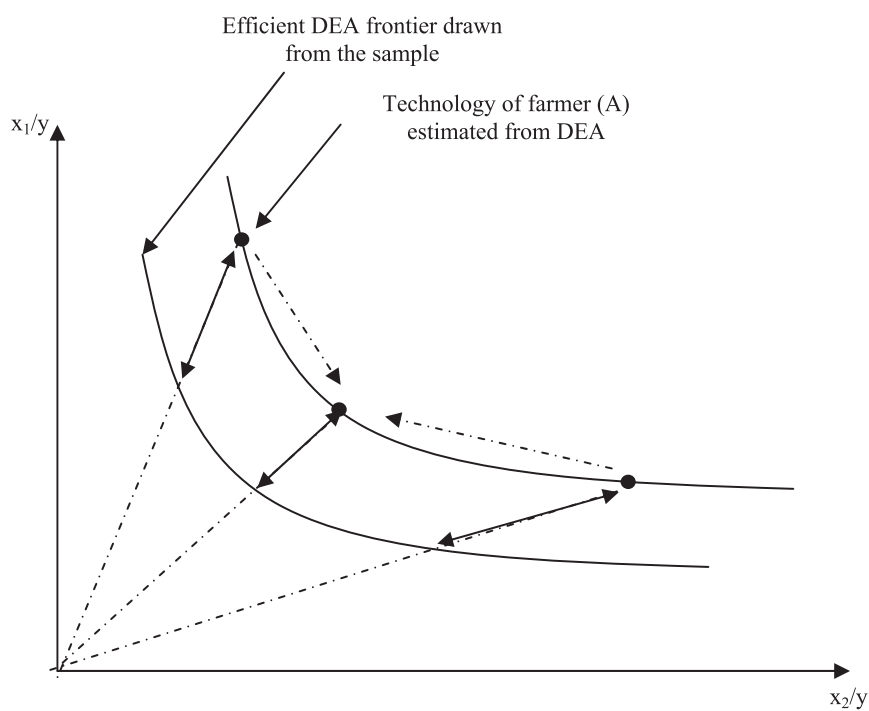

Fig. 2. Efficient technical frontier in the sample, and farmer (A)' technology drawn from information concerning his technical efficiency level.

inputs the producer does not face a price for water which reflects its value in alternative uses. In addition, lack of information about the production frontier may lead producers, such as farmer $A_{1}$, to use inputs inefficiently.

By providing education, support, and guidance to farmer $A_{1}$ concerning the frontier where profits are higher for each level of input use, the producer could be encouraged to use the existing management practices more efficiently or to adopt alternative ones. Once on the frontier $\mathrm{F}$, the producer could operate according to Good Agricultural Practice (point $\mathrm{C}$ ) which would maintain existing water use levels and at the same time increase profits. However, without any regulation or price for use of the water resource the producer could just as well operate on the segment C-D. Water use associated with the production possibilities on this part of the frontier would even be higher than in the original situation. In addition, thanks to the educational assistance our farmer could change to the more productive technology G. This adds to the possibility that education about production practices might lead to increased water use. Thus, educational assistance alone is not necessarily sufficient to ensure that water policy quantity goals are met.

Now assume that in addition to educational services, water pricing is implemented to control water use levels to $W_{s}$. To see how a uniform water price affects producers differently we compare technology F and technology G. Technology G is more advanced; per unit of water relatively more profit is generated. These higher marginal returns imply that the user of technology G can afford to pay a higher water price. The efficient user of this technology will likely be close to I on frontier $\mathrm{G}$. The ratio $\mathrm{P}_{\mathrm{Y}} / \mathrm{P}_{\mathrm{W}}$ reflects the price that needs to be introduced to make the efficient user of technology $G$ reduce his water to meet the target $\mathrm{W}_{\mathrm{s}}$. If the same water price would be introduced for users of technology $\mathrm{F}$ they would incur significant larger losses in profit due to its high price elasticity.

In summary, the effects of irrigation water pricing depend on: (a) the specific technology used by a farmer as reflected in the shape and level of the frontier and (b) the farmer's position with respect to this frontier as expressed by his level of efficiency.

\section{Methodology}

From the exposition in section 2, it follows that farm specific differences in technology and in efficiency are crucial to evaluate impacts of water pricing. Past studies commonly assume that

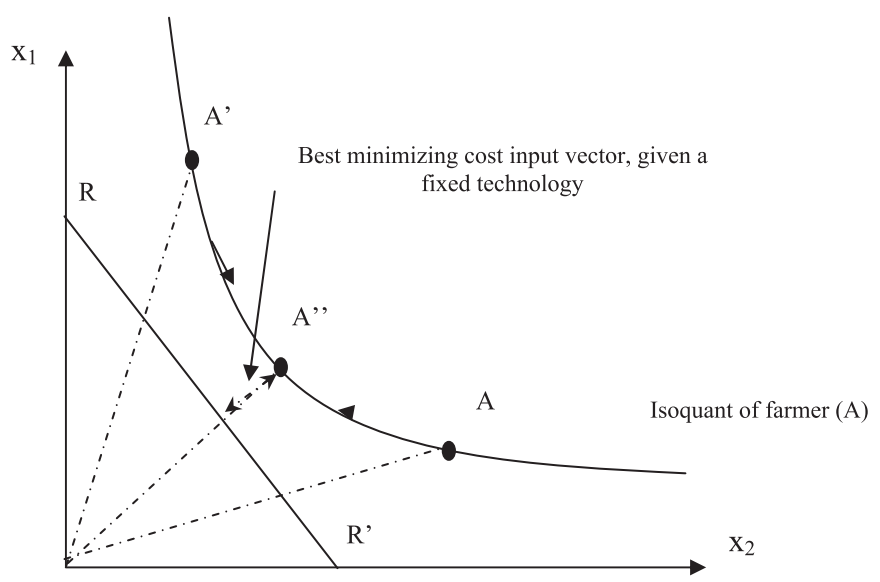

Fig. 3. Minimization of the input cost in the inverse DEA model.

producers behave rationally in terms of profit maximization in accordance with neoclassical economic theory (e.g., Gómez-Limón and Riesgo, 2004; Liao et al., 2007).

According to the normative mathematical approach, farmers would use their water allowances depending on the productivity (marginal value of water) that water generates in their farms taking into account the soil and climate conditions. Such models mainly provide prediction of changes in cropping patterns resulting from different water pricing policies. Most of these models use predetermined fixed ratios between inputs and outputs, assuming that substitution between different production factors is minimal or even non existent. This drawback can be overcome by using non-linear methods incorporating some production functions (or engineering production functions estimated from biophysical models).

In this study, we provide a novel methodology which addresses the previous models' disadvantages and develop a normative inverse DEA model that allows estimating the effect of water pricing on various inputs demand at the level of the individual farm. Moreover, the model allows for changes in the relative-use of the production factors (including factor substitution and complementarity) when the irrigation water price changes. Furthermore, the model does not need any prior functional or parametric specification. All results are provided at an individual level allowing case-by-case information for policy and decision makers.

The model application consists of following three steps: (a) calculation of the efficiency score for each farm using a standard DEA model, (b) calibration of an inverse DEA model for each farm based on the individual efficiency measures as a representation of the production technology, and (c) application of the inverse model to simulate the impact of water pricing policies on farm specific water demand.

\subsection{Inverse DEA model for inputs demand estimation}

In recent years there have been a number of papers presenting and using various "inverse optimization problems" mainly in Geophysical sciences, Medical imaging, and Traffic equilibrium ${ }^{3}$ (Ahuja and Orlin, 2001). Generally, in an inverse optimization problem, we have a given feasible solution which is not an optimal solution under the current parameter values of the system. The objective is then to adjust these parameter values as little as possible so that the feasible solution becomes the optimal one under the new adjusted parameter values (Wei et al., 2000).

\footnotetext{
${ }^{3}$ see Ahuja and Orlin 2001 and Tarantola 1987 for more details about applications of the inverse optimization.
} 
Table 1

Basic characteristics of LB and FJ WUAs.

\begin{tabular}{lll}
\hline & Fondok Jdid & Lebna Barrage \\
\hline Province & Grombalia & Mida \\
Rainfall $(\mathrm{mm})$ & $400-600$ & $400-500$ \\
Date of creation & 1998 & 1996 \\
Irrigated surface (Ha) & 1025 & 409 \\
Source of water & aquifers, North & Lebna dam, north \\
& water transfer & water transfer \\
Distribution mode & on request & On request \\
Price ${ }^{\mathrm{a}}\left(\mathrm{TND} / \mathrm{m}^{3}\right)$ & 0.048 & 0.068 \\
Irrigation technology & Drip, sprinkle, gravity & Drip, sprinkle, gravity \\
Main crops & Vegetables, & Vegetables, cereals \\
& cereals, Grapes & 108 \\
Number of members & 161 & 32 \\
Sample & 30 & \\
\hline Source: Groupements de Développement Agricole (2006). Rapports d'activités, GDA. \\
a Average exchange rate at the time of data collection 1 TND = 0.55 $€$.
\end{tabular}

Wei et al. (2000) proposed, for the first time, an "inverse" DEA model for short term input and output estimation. The basic idea was to extend the principle of "inverse optimization" to the context of non-parametric production functions. As mentioned above, in a general inverse optimization problem, we are interested in either adjusting constraint parameters such that a given feasible solution becomes optimal or varying constraint parameters such that the optimal objective value remains unchanged (Yan et al., 2002). In case of DEA optimization models, inputs and outputs quantities of all DMU are considered as parameters. This means that aninverse DEA model will obviously deal with input/output analysis within the framework of non-parametric production functions. Explicitly, it discusses the problem of determining the best possible output (input) level for a given input (output) level under the condition that the optimal objective value (efficiency score of DMU under analysis) of the standard DEA model remains the same. This means that such analysis of resource allocation is only valid in a short term perspective since the internal technical structure of a DMU may not change dramatically in such a period.

Despite its clear mathematical development, this type of inverse DEA model was never applied, at our knowledge, in the economic field for resolving problems of performance forecasting or of resource allocation. The current work is nevertheless closely related to the work on water pricing by Speelman et al. (2009). This research line implies a new avenue for DEA use in production analysis, planning and forecasting. In existing DEA literature, the problem of resource reallocation is dealt with only for purpose of guiding an inefficient DMU shifting along the direction of a projected ray from its current position onto the frontier (Yan et al., 2002) which is a completely different perspective from what we are trying to analyze this paper.

Based on Wei et al. (2000) we present our inverse inputoriented DEA model as following:

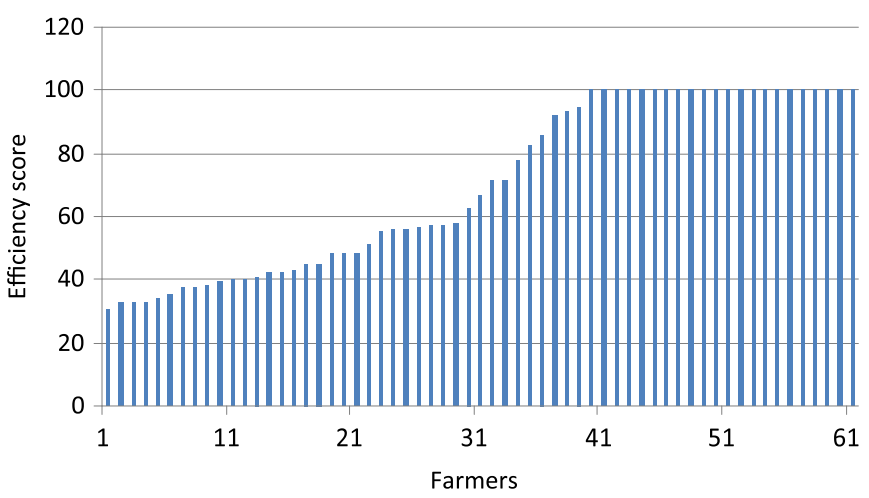

Fig. 4. Distribution of farmers by efficiency-groups.

Suppose a set of $\mathrm{n}$ Decision Making Units $\left(D U_{j}: j=1,2, \ldots, n\right)$, which produce multiple outputs $y_{r j}(r=1,2, \ldots, s)$, by utilizing multiple inputs $x_{i j}(i=1,2, \ldots, m)$. Let the inputs and outputs for $D M U_{j}$ be $X_{j}\left(x_{1 j}, x_{2 j}, \ldots, x_{m j}\right)$ and $Y_{j}\left(y_{1 j}, y_{2 j}, \ldots, y_{s j}\right)$, respectively. $X_{j}>0$, and $Y_{j}>0$ for all $j=1,2, \ldots, n$. When a, $D M U_{0}, 0 \in(1,2, \ldots, n)$, is under evaluation, then we can consider the following generalized DEA model Banker et al. (1984) (1):

$$
\begin{aligned}
& \operatorname{Min} \theta \\
& \text { s.t. } \sum_{j=1}^{n} X_{j} \lambda_{j} \leq x_{0} \theta \\
& \sum_{j=1}^{n} Y_{j} \lambda_{j} \geq y_{0} \\
& \sum_{j=1}^{n} \lambda_{j}=1 \\
& \lambda_{j} \geq 0 \quad \forall, j=1, \ldots, n
\end{aligned}
$$

If we resolve the model (1) for each DMU, we obtain a technical efficiency value $(\theta)$ for each of them. By resolving model 1, we also obtain a set of peers for each DMU. The peers are located on the frontier and serve as reference points (or efficient farmers) for calculating the efficiency of a given (non efficient) DMU. Then we may consider the following question: if the efficiency index $\theta$ for a $D M U_{0}$ remains unchanged, but the $D M U_{0}$ is obliged to decrease its outputs level, how much should the inputs of the $D M U_{0}$ decrease? To reply to this question suppose the outputs of $D M U_{0}$ are decreased from $Y_{0}$ to $\beta_{0}=Y_{0}-\Delta Y_{0}$, where the vector $\Delta Y_{0}>0$. We need then to estimate the input vector $\alpha_{0}^{*}=\left(\alpha_{10}^{*}, \alpha_{20}^{*}, \ldots, \alpha_{m 0}^{*}\right)=$ $x_{0}-\Delta x_{0}, \Delta x_{0} \geq 0$ provided that the efficiency index of $D M U_{0}$ is still $\theta$.

Suppose a new $D M U_{n+1}$ which represents $D M U_{0}$ after changing the inputs and outputs. We can then consider the following mathematical program (2) in order to calculate the efficiency of

\begin{tabular}{|c|c|c|c|c|c|c|c|c|c|}
\hline \multicolumn{6}{|l|}{ FJ area } & \multicolumn{4}{|l|}{ LB area } \\
\hline Variable $^{\#}$ & Dimension & Mean & SD & Min & Max & Mean & SD & Min & Max \\
\hline Output & TND & $\begin{array}{l}17615.8 \\
\left(1750^{a}\right)\end{array}$ & 23982.5 & 358 & 99048 & $\begin{array}{l}5645.2 \\
\left(2010^{\mathrm{a}}\right)\end{array}$ & 12163.4 & 405 & 13885.2 \\
\hline Land & $\mathrm{Ha}$ & 10 & 19.7 & 0.36 & 99 & 2.8 & 4.6 & 0.3 & 27 \\
\hline Capital & TND & 5798.3 & 7142.5 & 500 & 30000 & 3619 & 2673 & 200 & 15000 \\
\hline Labor & Days & 225.1 & 391.1 & 5.4 & 1859 & 93.5 & 188 & 4.2 & 1080 \\
\hline Water & M3 & 19819.5 & 36736.8 & 100 & 184190 & 13789.1 & 23683 & 600 & 135000 \\
\hline Fertilizers & TND & $\begin{array}{l}4890 \\
\left(28 \mathrm{~kg} / \mathrm{ha}^{\mathrm{b}}\right)\end{array}$ & 7024.5 & 99 & 29400 & $\begin{array}{l}8589.8 \\
\left(58 \mathrm{~kg} / \mathrm{ha}^{\mathrm{b}}\right)\end{array}$ & 37873 & 200 & 216000 \\
\hline
\end{tabular}
$D M U_{n+1}$ :

Table 2

Descriptive statistics of the inputs/outputs used in the DEA models (LB and FJ areas).

\# All values in the table are presented in unit/average farm.

a Average revenue per hectare.

b Average fertilizers use per ha SD: Standard Deviation. 


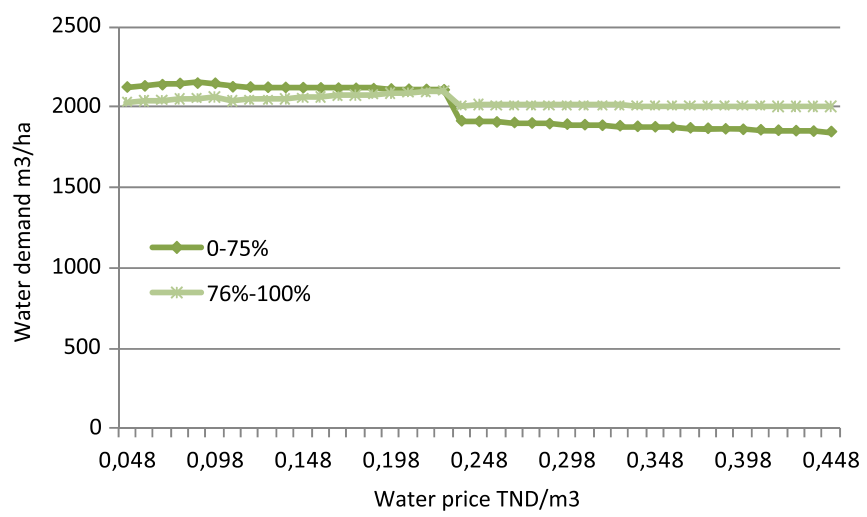

Fig. 5. Average water use per hectare for each efficiency-group.

$$
\begin{aligned}
& \operatorname{Min} \theta^{t} \\
& \text { s.t. } \sum_{j=1}^{n} X_{j} \lambda_{j}+\alpha_{0}^{*} \lambda_{n+1} \leq \alpha_{0}^{*} \theta^{t} \\
& \sum_{j=1}^{n} Y_{j} \lambda_{j}+\beta_{0} \lambda_{n+1} \geq \beta_{0} \\
& \sum_{j=1}^{n} \lambda_{j}=1 \\
& \lambda_{j} \geq 0 \forall, j=1, \ldots, n ; \lambda_{n+1} \geq 0
\end{aligned}
$$

The unique variable in this model 2 is $\alpha_{0}^{*}$, given that $\theta^{t}=\theta$, and $\beta_{0}$ fixed a-priory. Once we have an optimal value of the parameter $\alpha_{0}^{*}$, we can then write: Efficiency score $\left(\alpha_{0}^{*}, \beta_{0}\right)=$ Efficiency $\operatorname{score}\left(x_{0}, y_{0}\right)$.

As discussed in model (1), $\theta$ represents the relative efficiency of the $D M U_{0}$ under the present technology. Such technology conditions are not supposed to change in the short term. Using this technology information in addition to model (2), we can then present the following model (3) (adapted from Wei et al., 2000; Yan et al., 2002). Model (3) estimates the needed changes in the input combination when a reduction of the output level is expected.

$$
\begin{aligned}
& \operatorname{Min}\left(\alpha_{1,0}, \alpha_{2,0}, \ldots, \alpha_{m, 0}\right) \\
& \text { s.t. } \sum_{j=1}^{n} X_{j} \lambda_{j} \leq \alpha_{0} \theta \\
& \sum_{j=1}^{n} Y_{j} \lambda_{j} \geq \beta_{0} \\
& \sum_{j=1}^{n} \lambda_{j}=1 \\
& \alpha_{0} \leq x_{0} \\
& \lambda_{j} \geq 0 \quad \forall, j=1, \ldots, n ;
\end{aligned}
$$

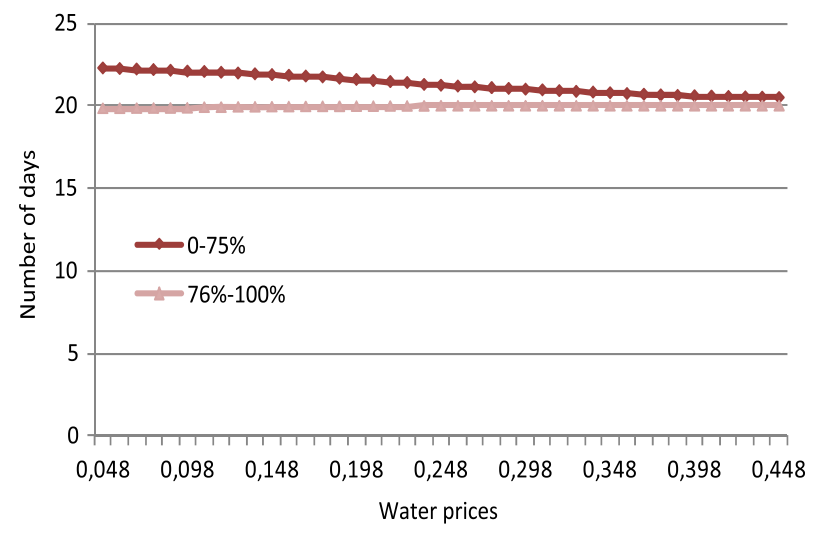

Table 3

Different farm size-groups selected in Cap Bon region.

\begin{tabular}{llll}
\hline Groups & $\begin{array}{l}\text { Percentage in } \\
\text { the sample }\end{array}$ & $\begin{array}{l}\text { average surface/ } \\
\text { farm (ha) }\end{array}$ & $\begin{array}{l}\text { average Technical } \\
\text { efficiency }\end{array}$ \\
\hline Size $>6$ ha & $20 \%$ & 23.7 & 0.85 \\
2 ha $<$ size $<=6$ ha & $36 \%$ & 3.3 & 0.59 \\
$0<$ size $<=2$ ha & $43 \%$ & 1.2 & 0.69 \\
\hline
\end{tabular}

Where $\beta_{0}$ and $\alpha_{0}$ are defined as before, and $\theta$ represents the technology of $D M U_{0}$ already estimated from program (1).

Now assume $p_{i}=\left(p_{1}, p_{2}, \ldots, p_{m}\right)$ the prices of the $\mathrm{m}^{\text {th }}$ inputs, and $p>0$. Suppose also that $y_{0}$ is expressed in a monetary term as being the net revenue of farmers; then we propose the following weighted sum model (4):

$$
\begin{aligned}
& \operatorname{Max} R_{0}=y_{0}-\sum_{i=1}^{m} p_{\text {sim }} \cdot \alpha_{i, 0} \\
& \text { s.t. } \sum_{j=1}^{n} X_{j} \lambda_{j} \leq \alpha_{0} \theta \\
& \sum_{j=1}^{n} Y_{j} \lambda_{j} \geq y_{0} \\
& \sum_{j=1}^{n} \lambda_{j}=1 \\
& \alpha_{0, \text { terre }} \leq x_{0, \text { terre }} \quad \forall, p_{\text {sim }} \geq p_{i} \\
& \lambda_{j} \geq 0 \quad \forall, j=1, \ldots, n ;
\end{aligned}
$$

Variables of this model are $\alpha_{i, 0}$ and $\lambda_{j}$. The rest of parameters are known before simulation. $p_{i}$ and $p_{s i m}$ are respectively the original and the simulated input price vectors and $y_{0}$ is the observed farmers' net revenue expressed in monetary term. $R$ is the expected revenue which the farmer is trying to maximize under different $p_{\text {sim }}$ scenarios. $\mathrm{R}$ is expressed as the total amount of revenue that is currently being obtained (by the farmer) minus the extra cost due to the change in the input combination when $p_{\text {sim }}$ changes. The remaining parameters are defined the same as in the models 1,2 and 3. This model assumes a fixed technical efficiency while allowing the $D M U$ to adjust its allocative efficiency when input prices change (Figs. 2 and 3). The input constraint can be read as if we would be prepared to radially reduce inputs in order to achieve the amount of revenue (described above), this reduction would be done according to the farmer technology. Of course, this technology is initially determined by reference to a set of peer DMUs weighted according to an optimal $\lambda_{j}$ combination and obtained when resolving model 1 for a given DMU. This set of peers can change when $p_{\text {sim }}$ changes, indicating that when relative prices changes, other DMU could be more useful in describing the optimal behavior of the farmer (under simulation) while preserving his initial

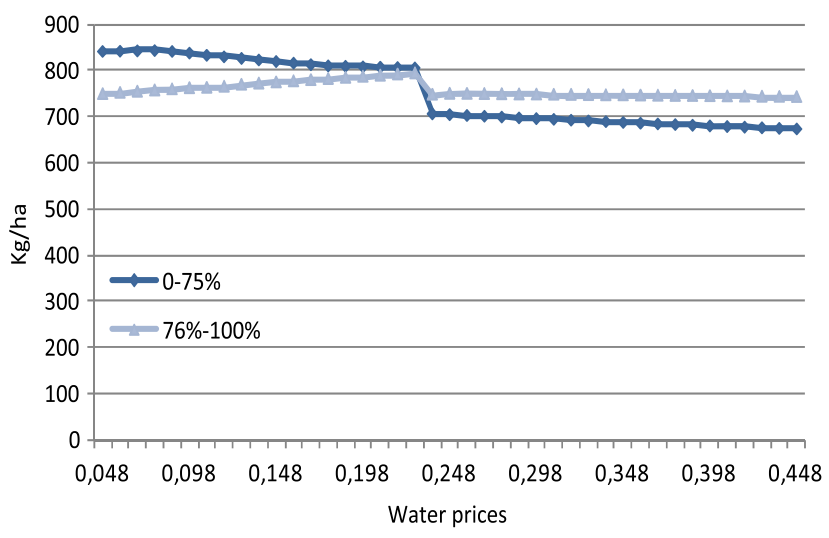

Fig. 6. Average Labor (left) and fertilizers (right) use per ha for different efficiency-group. 


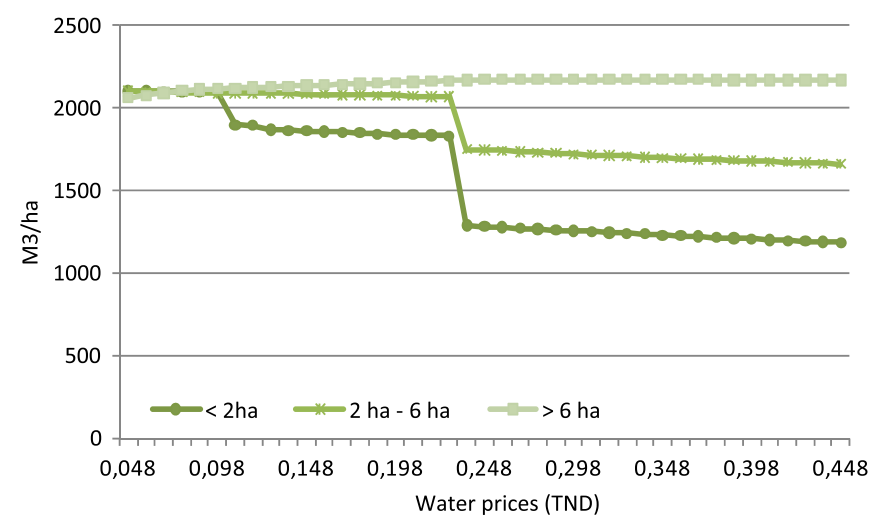

Fig. 7. Average per hectare water use for each size-group.

technology frontier. Similarly to model (3) the functional form of model (4) allows the estimation of the needed changes in the input combination when a reduction of the farmer revenue level is expected.

Fig. 2 shows the DEA frontier drawn for the entire sample in addition to the technology of the farmer (A). Fig. 2 also shows how the farmer $(A)$ will change its position on the isoquant when input prices ( $\mathrm{p} 1$ and/or $\mathrm{p} 2$ ) change.

The input price ratio is represented in Fig. 3 by the line RR'. By running the model (4), we will look for a position on the isoquant of farmer (A), which minimizes the farmer's input cost taken into account the new input price ratio. This minimization is equivalent to a maximization of the allocative efficiency of the farmer. Farmer (A) will try to minimize his input cost as far as his technical production function allow.

\subsection{Case study and data collection}

The decision to consider the Cap Bon region in Tunisia is justified by its importance in terms of national agricultural production, crop diversification, extension of irrigated perimeters and water scarcity. The increasing competition for water between users (agriculture, industry and tourism) in Cap Bon clearly demonstrates the relative and increasing shortage of water.

The irrigated sector in the Cap Bon region has experienced considerable development. It accounts for $13.3 \%$ of Tunisian irrigated land and the region thereby occupies a second place at national level in terms of irrigated land area. $71 \%$ of the Cap Bon irrigated area belongs to small and medium-sized farms. Intensively irrigated land amounts to approximately 47600 ha 19100 ha of which are situated within public irrigation perimeters (CRDA Nabeul, 2006).

Errors in DEA models can arise from two different sources. 1Non-parametric approach of estimating the efficiency scores: in this type of models data errors are treated as inefficiencies. 2Sampling and representativeness: usually, in parametric approaches, the sample has to be larger than a minimum size to have non biased and valid estimation results. However, because we are using a non-parametric model, the sample size is not important anymore but the representativeness becomes an important issue. As mentioned above, in our study, we proceeded with a random sampling procedure of farmers and rejection of outlier observations based on simple observation complemented by a Boxplot description.

Our data was collected, during the period March-May 2007, from 62 selected farmers belonging to neighbouring areas within the Cap Bon region: the Fondok Jedid (FJ) and Lebna Barrage (LB).
Each area is managed by one WUA. The dataset includes $18.7 \%$ (30 farmers) and 30\% (32 farmers) of the total number of farmers' adherent to the FJ and LB WUAs, respectively (Table 1). Characteristics of both associations are presented in Table 1. It is important to notice that in the FJ area, farmers have access both to surface water (publicly provided by WUA) and groundwater (from private wells).

One output and five inputs were chosen for the calculation of farming efficiency in FJ and LB. The output consisted of the total farm income, while inputs considered are labor, volume of water consumed, fertilizers, land, and capital. Labor is assessed in terms of the number of working days; water consumption is expressed in terms of cubic meters ${ }^{4}$ (for FJ farmers, groundwater and surface water were summed up under the same vector when calculating the efficiency scores); and fertilizers in terms of $\mathrm{kg}$ applied. Land and capital are considered as fixed inputs. The amount of capital used in our calculation only includes the machinery and water saving installations existing on the farm. Basic statistics for the farmers' inputs/outputs are shown in Table 2. A common frontier was drawn for both groups. This will allow farmers from a given group to have peers from the second group when irrigation prices increase. In this manner, shifts from a particular irrigated system toward another can be captured.

As mentioned above, we expect that the most efficient farmers will be more inelastic in their irrigation demand. Also, we expect that small-size farmers will be most affected by the increasing irrigation prices policy. Thus, due to the specific empirical validation needed in this paper, farmers will be grouped according to:

- Their technical efficiency level: two groups were selected in order to emphasize the differences of the water demand elasticity between the most and the less efficient farmers,

- Their size: farmers of the sample were also grouped into three size-groups in order to show the differences of the water demand elasticity between the largest and the smallest farms,

- Their Water User Association (WUA): farmers were finally grouped into two groups, according to the WUA to which they belong. This aims to compare the water demand functions of both irrigated areas.

It is important to mention that both public and groundwater were aggregated into unique input vector when simulating demand functions for efficiency and size-based groups. However, these two types of water were considered as separate vectors when calculating the input demand functions for FJ WUA. For this latter area, we then derived both public and groundwater demands in order to investigate the form of the conjunctive use of both types of water in the region.

\section{Results}

\subsection{Input demand functions per efficiency-group}

In order to distinguish the differential impact of the increasing volumetric pricing policy on various farmers-groups by technical efficiency level, we divided the 62 farmers of our sample into two groups defined as follows (i) group1: farmers with an efficiency score from 0 to $75 \%$; and (ii) group2: farmers with an efficiency level on the $76 \%-100 \%$ interval (Fig. 4). These efficiency intervals were chosen arbitrary. By running the model (4) for each farmers and summing the new water demands (corresponding to each of

\footnotetext{
4 The pricing method applied in the region is volumetric pricing. In each farm, water meters are installed and individual water consumption is measured and charged by the water users' association.
} 

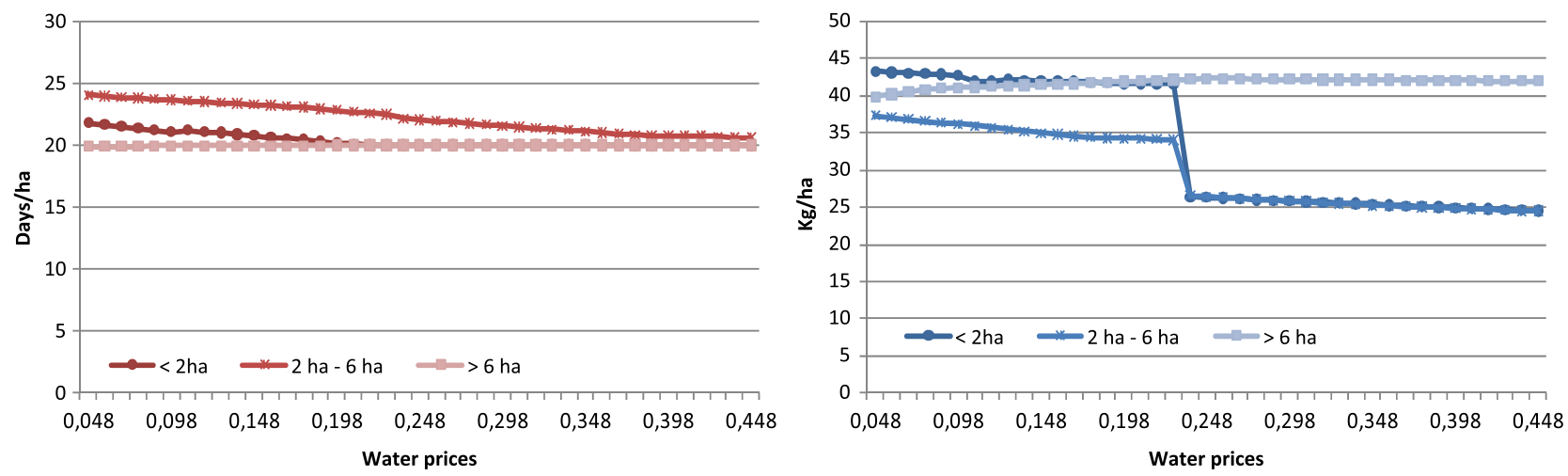

Fig. 8. Average Labor (left) and fertilizers (right) use per ha for different size-goups.

the tested prices) of farmers in each group, we obtained the irrigation demand functions represented in Fig. 5.

It is clear from Fig. 5 that the group which will be affected the most by increasing irrigation water prices is the less efficient one. Water use per ha for this last group falls from $2126.5 \mathrm{~m} 3 /$ ha to $1840 \mathrm{~m}^{3} /$ ha $(-13.5 \%)$ when irrigation water prices changes from $0.048 \mathrm{TND} / \mathrm{m}^{3}$ to a price of $0.448 \mathrm{TND} / \mathrm{m}^{3}$. The latter price is supposed to cover all variable and fixed production costs of the irrigation water. This could be interpreted by a shift toward more water-valorizing crops or simply by devoting more surface on the farm to rainfed crops.

Water use per ha in the most efficient group was reduced by only $1.3 \%$. The most efficient group will hardly react to the change in irrigation water prices.

Concerning fertilizer use, both efficiency-groups show a similar sloping demand function to irrigation water demand when the irrigation prices increases (Fig. 6). The average decrease in fertilizers' use however is not significant for the case of the most efficient group while it can reach around $200 \mathrm{~kg} / \mathrm{ha}$ for groups 1. Fig. 6 also shows that for the most efficient farmers, water and labor seem to be substitutable. In fact, average labor demand increased for this latter group when irrigation prices changed from 0.048 to 0.448 TND while average water demand per ha decreased for the same change of irrigation prices.

\subsection{Input demand functions per size-category group}

In order to see if the irrigation water pricing policy has any differential impact on various farm size-groups, we selected the following three groups of farmers based on their size (Table 3). For each size-group and irrigation price, individual inputs demand

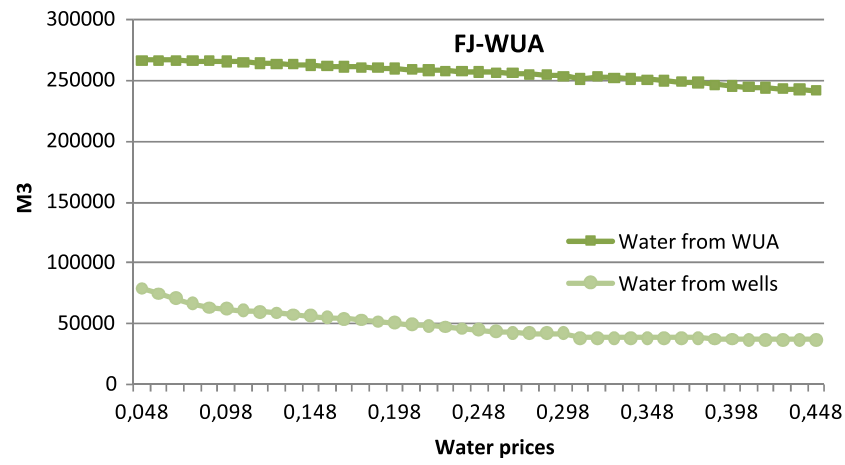

were summed and represented in the Figs. 7 and 8 at different price level.

Fig. 7 shows that small-size farms will be the most affected by higher irrigation prices. Their water demand decreases by 33\% when the price of water equals a full cost recovery price. Our calculations also show that the total land use, of all farmers in this group, will increase with $15.3 \%$ for the same price change. In contrasts, the large-size-group (which is more efficient, Table 3) decreases its total water use by $13 \%$ and the cropped area by $17 \%$ (upward shape in Fig. 7). In fact this interaction explains that water demand/ha is rather inelastic for this group of farms.

As shown in Fig. 8, the largest farmers will neither reduce the use per ha of labor or fertilizers. This proves that these farmers are close to the maximum intensification level permitted by the currently available technology in the region. By keeping their level of water and other inputs use/ha constant and reducing their cropped area at the same time, these farmers are in fact reducing the scale of their operation. We also notice that a water price of $0.220 \mathrm{TND} / \mathrm{m}^{3}$ leads to parallel jumps in both fertilizer and water demand curves of small and medium size farmers (see Figs. 7 and 8).

\subsection{Comparison of input demand between FJ and LB areas}

As mentioned above, public water and groundwater were considered as two different inputs when simulating the water demand functions in FJ. However, they were aggregated in the same input vector for the case of LB where farmers only use public water supplied by the WUA. Fig. 9 shows the trend of total irrigation water use in both WUA when irrigation prices increases.

From Fig. 9 it appears that public and groundwater are complementary inputs since the demand of both decreases with an increase in the irrigation prices of public water. Despite the fact that

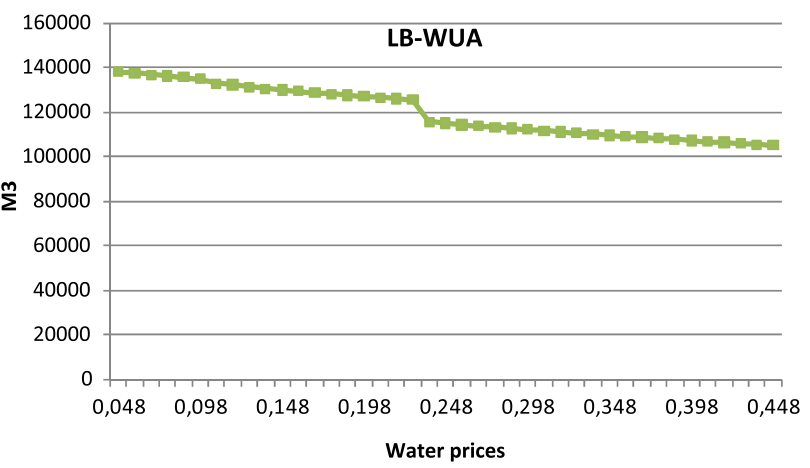

Fig. 9. Total water consumption in both FJ and LB. 


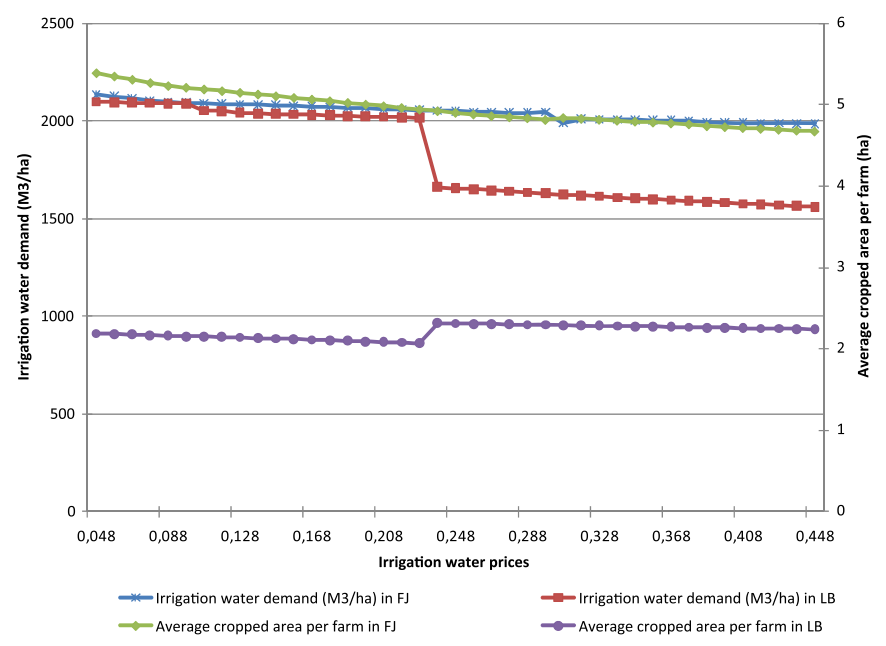

Fig. 10. Irrigation water and land demand functions in both FJ and LB WUAs.

current water pumping cost (around $0.033 \mathrm{TND} / \mathrm{m}^{3}$ ) is much lower than the public water price $\left(0.068 \mathrm{TND} / \mathrm{m}^{3}\right)$, farmers in $\mathrm{FJ}$, even those holding a well, continue using water from public sources (according to our survey). This complementary relationship could be due to the high salinity of groundwater in the studied region. Farmers may have to mix public and groundwater to obtain water with a sufficient quality.

Total water demand in FJ decreased by $14.2 \%$ when irrigation prices increased from 0.048 to 0.440 TND. However, total water consumption in LB decreased with $24 \%$ under the same price change. The trend in cropped area per farm and water consumption per ha in both areas are shown in Fig. 10.

At the current water price $\left(0.048 \mathrm{TND} / \mathrm{m}^{3}\right)$, FJ farmers consume on average $2136.6 \mathrm{~m}^{3} /$ ha, which almost equals the optimal level consumed in LB (2099.8 $\mathrm{m}^{3} /$ ha $)$ under the assumption that farmers are maximizing their allocative efficiency. However, the response to an increase in the irrigation water price is markedly different in the two areas. In FJ, the water demand/ha was found to be inelastic, while demand decreased considerably in LB. Nevertheless also in this second area, an inelastic price segment of the water demand curves was recorded. This segment coincides with prices at which farmers are insensitive to water price increases. When irrigation price reaches $0.228 \mathrm{TND} / \mathrm{m}^{3}$ (almost triple of the current price), LB farmers suddenly decreased their irrigation water demand. This decrease is accompanied with an increase in the average cropped area from 2 ha to 2.3 ha per farm. This shows that in LB a substitutability relationship exists between water and land factors.

The increase of irrigation price would result in the loss of agricultural employment in LB (Fig. 12). According to the findings in the latter section, small-size farms reduced their level of labor use as a reaction to the price change. The evolution of the fertilizer demand is again similar to the water demand functions. The increase of irrigation prices will not affect the use of fertilizers in FJ. By contrast, LB farmers will reduce the use of this input by $26 \%$ on average, when water prices reach a full recovery cost.

\section{Discussion}

The result that water demand elasticity is highly dependent on technical efficiency/technology is in line with findings of VarelaOrtega et al. (1998). They compared the price elasticity of water demand in three regions in Spain. They concluded that in 'old' irrigation schemes, where water application techniques are relatively inefficient, the response to increasing water charges is much higher than in the modern systems with drip irrigation. The authors conclude that the technical endowment in an agricultural district has a major effect on its response to water pricing. Albiac et al. (2007), Gómez-Limón and Riesgo (2004), and Berbel \& Gómez-Limón also report very low elasticities for irrigation water demand in case studies in Spain. For their study on the Tunisian case (Kairouan region in the central part of Tunisia), Poussin et al., (2008) also found that a major increase (50\%) in the cost of water affected only a minority of farms (in terms of revenue), who are consuming only $17 \%$ of the total irrigation water in the region.

Fertilizer and irrigation water demand show a very similar trend with water price changes in all demand functions estimated. According to these observations, a complementary relationship between the latter two factors exists in the studied area. This result is consistent with empirical studies that examine inputs interactions in irrigated agriculture both through field experiments (e.g., Prihar et al., 1989; Thompson et al., 2000) and modeling analysis (e.g., Bartolini et al., 2007; Chebil et al., 2004; Cai et al., 2008; Speelman et al., 2009). The complementarity between water and fertilizers in Tunisia was also reported by Chebil et al. (2004) when they studied the technical progress of the irrigated systems in Teboulba region. Besides, Cai et al. (2008), in their study of the substitution between water and other agricultural inputs when irrigation prices increases in the Maipo River basin in Chile, found monotonous substitution relationships between water and irrigation investment, labor, machinery and pesticides, respectively. In this latter study, a clear complementary relationship between water and fertilizers was also demonstrated.

The irrigation demand functions obtained for FJ and LB are in line with the simulation results of Chebil et al. (2008) using a multiobjective programming model at the aggregated level using the same data used in this study (Fig. 11). Their objective function integrates the risk behavior (calculated from secondary data about
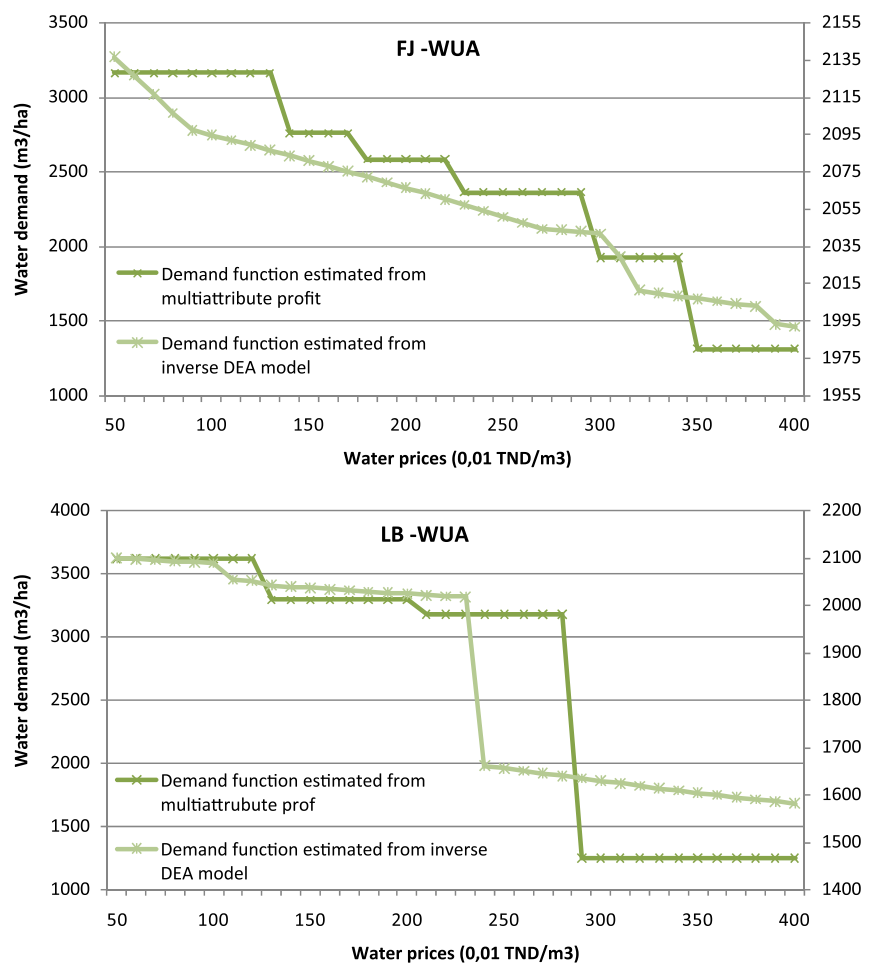

Fig. 11. Comparison between water demand functions estimated (using the same data sample) from a multi-attribute utility function (Chebil et al., 2008) and from inverse DEA model. 

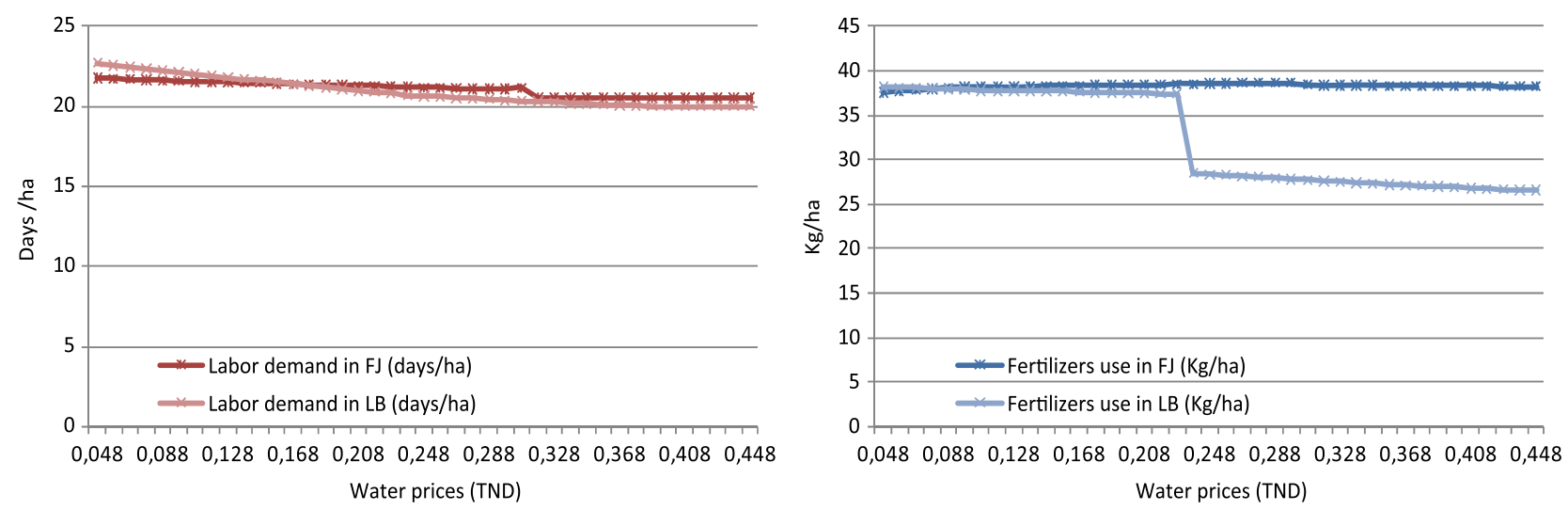

Fig. 12. Labor and fertilizers demands for various irrigation prices in both WUA.

regional yields and prices) in addition to profit maximizing objective. Our inverse DEA model is able to reproduce an almost identical pattern without prior functional or parametric specifications of farm behavior. Also, our model used a minimum amount of data. Moreover, optimal results obtained from the inverse DEA model for each farm are not optimal in an absolute sense but relatively to the best performer in the sample, which is a clear advantage compared to other normative models.

Also the comparison of the trend in inputs demand functions between FJ and LB, when a similar irrigation pricing policy is applied in both regions, reveal many important findings. A first remark concerns the conjunctive use of public and groundwater in FJ area. In fact, these two types of water were unexpectedly found to be complementary. Currently, the average pumping cost in $\mathrm{FJ}$ is around $0.033 \mathrm{TND} / \mathrm{m}^{3}$. Despite the fact that this cost is much lower than the cost of public water distributed by WUA $\left(0.068 \mathrm{TND} / \mathrm{m}^{3}\right)$, most of the farmers are presently combining both resources. According to our survey, 98\% of farmers in FJ district have a well on their farms and $32.3 \%$ of these wells provide salty water (more than $1.5 \mathrm{~g} / \mathrm{L}$ ). $36 \%$ of farmers in FJ consider the quality of water as the main irrigation constraint. Thus, the complementary relationship between both types of water seems to be specific to the context of our study area. This result should not be generalized.

Another remark concerns the changes in land structure in both regions as consequence of the pricing policy. In FJ, the average cropped area per farm decreased by $13 \%$ (from 5.4 ha/farm to 4.7 ha/farm) when irrigation price changed from the current situation to a cost recovery price level. This decrease of the land use is also accompanied with a decrease in the water and labor demand. All of this shows clearly that, in average, FJ farmers will reduces their scale of operation as response to the irrigation pricing policy simulated. By contrast, farmers in LB increased their land use while reducing their irrigation water, fertilizers and labor demands. As presented in Fig. 7, smaller farmers (less than 2 ha), currently use around $2102 \mathrm{~m}^{3} /$ ha of irrigation water reduce their consumption to $1180 \mathrm{~m}^{3} /$ ha (56\% of current optimal consumption) when irrigation prices reach the cost recovery level. For the same price change, small farmers also reduced their fertilizers and labor use by $43 \%$ and $8 \%$, respectively. However, their average cultivated land per farm increased by $15 \%$. This trend can only be explained by a shift toward less water consuming crops, or by devoting a largest part of the farm for extensive rainfall crops.

The previous remark emphasises the probable threat for the irrigated activity in Tunisia of an increasing of water prices beyond a certain limit, knowing that on average FJ farmers are more efficient and larger than LB farmers. The smallest and less efficient farmers will in fact shift toward different cropping systems supposed to be more water-valorising (which is not easy for them without support of public authorities) while the most efficient and the largest farmers will start to reduce the scale of their operation. We also have to add the caveat that these changes are supposed to happen when farmers are maximizing their allocative efficiency, which is not always the case in real contexts.

\section{Conclusions}

Many studies have warned against the limited effect of water pricing in terms of irrigation water saving and even the negative economic and social impact of this tool in some specific cases. In this study, we propose a novel data-driven deductive methodology for estimating the impact of increasing water prices in Tunisia. This methodology is based on an inverse DEA model which takes into consideration the technical efficiency level of each individual farmer when estimating his irrigation water demand for different prices. The main results of our study can be summarized as follows:

Farmers' technical efficiency level is important factor deeply affecting the elasticity of their water demand. Under the assumption of full allocative efficiency for a given available technology, farmers who are most technically efficient will have the least elastic irrigation water demand. The most efficient farmers are better at valorising water resources. Thus they are able to afford higher irrigation prices than their less efficient colleagues. However, this will affect their cost and income structure. Potential effects on commodities prices can be then assessed. This latest point was not considered in the current study but will be interesting to include in future analyses.

A full cost recovery strategy will threat the livelihood of the small-size irrigated farmers if their technical efficiency will not improve (small farmers were found to be the less efficient and most elastic to water prices). These farmers will shift toward a cropping pattern using less water and more land when the price of water increases. More facilities such as credit access, training programs, market integration, etc. are needed to support these small-size farmers which are generally more constrained to improve their technical efficiency. These facilities will have also to support farmers shifting towards more productive patterns of production (benchmark in a region), and not towards an extensive less productive one. A shift towards more productive patterns is however not always easy especially for the small-size farmers due to constraints they face. If latter farmers will not be able to "jump" to the best performance frontier, then their financial sustainability will be in real threat.

On another hand, if the technical efficiency of these farmers could improve, then water saving objectives will be difficult to reach since their demand will become highly inelastic. This could in 
fact threat the sustainability of the irrigated activity which is crucial for Tunesia's national development and food safety. This last conclusion does not assume any technological improvement in the long run for the most efficient farmers. However, if the currently most efficient farmer would have access to an advanced water saving technology, then his efficient frontier could shift towards another more efficient pattern to ensure both water saving and irrigation intensification.

The implications of these main results are very important for the Tunisian context. As discussed in the introduction, the Tunisian water policy has three main objectives: full cost recovery, continuity of the irrigation activity, and water saving at the national level. Our empirical findings suggest that the current water pricing plus education policy is not suited to achieving these three objectives simultaneously. Specifically, according to our results improvement of technical efficiency and the currently available technologies will make water demand functions more and more inelastic.

Further research will address farmers' adjustment opportunities in more detail. Gardner (1983, cited in Ray, 2002) states that if water prices rise to reflect its opportunity cost, a rational farmer will have any or all of the four following responses: the farmer demands less water and leaves land fallow; applies less water to the crop accepting some yield loss; switches to less water-demanding crops; and/or invests in more efficient irrigation techniques. The changes in the inputs use combinations in our study show that farmers are indeed moving toward different cropping patterns but these are not necessary more water-valorizing patterns. More investigations have to be done in this direction.

Also, due to its normative nature, the model assumes maximum allocative efficiency of the farmers. But in fact, given the management capacity of each farmer, the margin for improving his allocative efficiency might be restricted. Thus in reality, not all farmers are maximizing their allocative efficiency given their current technical capacity. This limitation can be overcome by providing a positive version of model (4) by specifying a more flexible output function which, for instance, accounts some other attributes such as the farmer's risk attitude. This would be an interesting next step in the line of research on inverse DEA models.

\section{References}

Al Atiri R., 2007. Evolution institutionelle et réglementaire de la gestion de l'eau en Tunisie, Vers une participation accrue des usagers de l'eau ; in Sami Bouarfa, Marcel Kuper, Abdelhafid Debbarh (éditeurs scientifiques) 2007. L'avenir de l'agriculture irriguée en Méditerranée. Nouveaux arrangements institutionnels pour une gestion de la demande en eau. Actes du séminaire Wademed, Cahors, France, 6-7 novembre 2006. Cirad, Montpellier, France

Albiac, J., Playan, E., Martinez, Y., 2007. Instruments for water quantity and quality management in the agriculture in Aragon. Int. J. Water Resour. Dev. 23, 147-164.
Bar-Shira, Z., Finkelshtain, I., Simhon, A., 2006. Blockrate versus uniform water pricing in agriculture: an empirical analysis. Am. J. Agr. Econ. 88 (4), 986-999. doi:10.1111/j.1467-8276.2006.00911.

Bartolini, F., Bazzani, G.M., Gallerani, V., Raggi, M., Viaggi, D., 2007. The impact of water and agriculture policy scenarios on irrigated farming systems in Italy: an analysis based on farm level multi-attribute linear programming models. Agr Syst. 93, 90-114.

Berbel, J., Gómez-Limón, J.A., 2000. The impact of water-pricing policy in Spain: an analysis of three irrigated areas. Agr. Water Manage. 43, 219-238.

Cai, X., Ringler, C., Yun You, J., 2008. Substitution between water and other agricultural inputs: implications for water conservation in a River Basin context. Ecol. Econ. 66, 38-50.

Chebil, A., Lachaal, L., Dhehibi, B., Frija, A., 2004. Technical advances and irrigation water demand of protected vegetable crops in Tunisia: the case of Teboulba. Mediterranean. J. Econ. Agric. Environ. 4-N. 4/2005 (Dec).

Chebil. A, Thabet, C. Gomez-Limon. J.A., Zaibet, L. and Frija. A., 2008 Water demand and economic impact of irrigation water pricing in Cap Bon region (Tunisia): An application of multicriteria approach. Poster presented at the European Association of Agricultural Economics (EAAE) XIIth Congress-Ghent, August 26-29, 2008, Belgium Commissariat Régionale de Développement Agricole (CRDA) Nabeul., 2006. Rapports d'activités Annuels.

De Fraiture C., and Perry, C., 2002. Why is irrigation water demand irresponsive at low price ranges? World Bank Water Conference, Agadir, Moroco.2002

Easter, K.W., Liu, Y., 2007. Who pays for irrigation: cost recovery and water pricing? Water Policy 9, 285-303.

Gomez-Limon, J.A., Berbel, J., 2000. Multicriteria analysis of derived water demand functions: a Spanish case study. Agr Syst. 63 (1), 49-72.

Gómez-Limón, J.A., Riesgo, L., 2004. Irrigation water pricing: differential impacts on irrigated farms. Agr. Econ. 31, 47-66.

Grafton, R.Q., 2009. Economics of Water Resources. Elgar, Cheltenham.

Liao, Y., Giordano, M., Fraiture, C., 2007. An empirical analysis of the impacts of irrigation pricing reforms in China. Water Policy vol. 9, 45-60,.

Molle, F., Venot, J.P., Hassan, Y., 2008. Irrigation in the Jordan Valley: are water pricing policies overly optimistic? Agr. Water Manage. 95 (4), 427-438.

Perry, C., 2001. Water at any price? Issues and options in charging for irrigation water. Irrig. Drain 50, 1-7.

Prihar, S.S., Sandhu, K.S., Singh, M., Verma, H.N., Singh, R., 1989. Response of dryland wheat to small supplemental irrigation and fertilizer nitrogen in submontane Punjab. Fertil. Res. 21, 23-28.

Ray, I., 2002. Farm-level Incentives for Irrigation Efficiency: Some Lessons from an Indian Canal. Water Resources Update 121. January 2002. Universities Council on Water Resources.

Russell, C.S., Clark, C.D., Schuck, E.C., 2007. Economic Instruments for water management in the Middle East and North Africa. Int. J. Water Resour. Dev. 23. 659-677.

Singh, K., 2007. Rational pricing of water as an instrument of improving water use efficiency in the agricultural sector: a case study in Gujarat, India. Int. J. Water Resour. Dev. 23, 679-690.

Speelman, S., Buysse, J., Farolfi, S., Frija, A., D’Haese, M., D’Haese, L., 2009. Estimating the impact of water pricing on smallholder irrigators in North West province, South Africa. Agr. Water Manage. 96 (11), 1560-1566.

Thompson, T.L., Doerge, T.A., Godin, R.E., 2000. Nitrogen and water interactions in subsurface drip-irrigated cauliflower: I. Plant response. Am. J. Soil Sci. Soc. 64, 406-411.

Varela-Ortega, C., Sumpi, J.M., Garrido, A., Blanco, M., Iglesias, E., 1998. Water pricing policies, public decision making and farmers' response: Implication for water policy. Agr. Econ. 19, 193-202.

Webber, M., Barnett, J., Finlayson, B., Wang, M., 2008. Pricing China's irrigation water. Glob. Environ. Change 18 (4), 617-625.

Wei, Q., Zhang, J., Zhang, X., 2000. An inverse DEA model for inputs/outputs estimate. Eur. J. Oper. Res. 121, 151-163.

Yan, H., Wei, Q., Hao, G., 2002. DEA models for resource reallocation and production input/output estimation. Eur. J. Oper. Res. 136, 19-31. 